\title{
Hydrogen sulfide concentration in the milieu of the hydrated alanine dipeptide determines its polyproline II-beta propensity: Main chain contribution to the energetic origin of the formation of amyloid
}

\author{
Noemi G. Mirkin | Samuel Krimm
}

LSA Biophysics, University of Michigan, Ann Arbor, MI, U.S.A.

Correspondence

Samuel Krimm, LSA Biophysics, University of Michigan, 930 N. University Ave., Ann Arbor, MI 48109, U.S.A.

Email: skrimm@umich.edu

\begin{abstract}
In view of the observation that the concentration of hydrogen sulfide in brains with Alzheimer's disease (AD) is lower than that in normal brains and in line with our previous studies indicating that additional content in the aqueous environment (milieu) of a peptide can change its local energetic preference from a polyproline II $(P)$ to a $\beta$ conformation (and therefore its tendency to form the $\beta$-chain structures that lead to the amyloid plaques associated with the disease), we have studied the effect of $\mathrm{H}_{2} \mathrm{~S}$ concentration on such propensity in a simple model peptide, the alanine dipeptide (ADP). The two concentration states are represented by $\operatorname{ADP}\left(\mathrm{H}_{2} \mathrm{O}\right)_{18}\left(\mathrm{H}_{2} \mathrm{~S}\right)$ and $\operatorname{ADP}\left(\mathrm{H}_{2} \mathrm{O}\right)_{18}\left(\mathrm{H}_{2} \mathrm{~S}\right)_{2}$. Ab initio calculations of these structures show that the lowest energy of the former is a $\beta$ conformation while that of the latter is a $\mathrm{P}$, mirroring the observed $\mathrm{AD}$ results and strengthening our proposal that amyloid diseases are better viewed in the context of a protein milieu-folding paradigm.
\end{abstract}

\section{1 | INTRODUCTION}

Although inhalant hydrogen sulfide $\left(\mathrm{H}_{2} \mathrm{~S}\right)$ has long been known for its high toxicity, it has recently become evident that the $\mathrm{H}_{2} \mathrm{~S}$ produced in the brain plays a significant functional role as a neuromodulator. ${ }^{[1]}$ While the mechanisms in this role are still being investigated, ${ }^{[1]}$ it is currently known that the concentration of $\mathrm{H}_{2} \mathrm{~S}$ in the human brain has an important effect: low levels are associated with a high incidence of Alzheimer's disease (AD). ${ }^{[2]}$ This correlation is strengthened by the determination that increasing the concentration of $\mathrm{H}_{2} \mathrm{~S}$ in the brains of transgenic $A D$ mice is associated with a reduction in the size of the amyloid plaques associated with their symptoms of $A D .^{[3]}$ These plaques are formed from ca40-residue hydrogen-bonded $\beta A D$ peptide $(A \beta)$ chains, produced by enzymatic cleavage of a large precursor protein, that would normally be in an unordered (and thus soluble) functional state. ${ }^{[4]}$ It is natural to expect that the molecular origin of this structural change in the peptide would be sought, and from a Raman spectroscopic study of amyloids of hen egg white lysozyme it was concluded that the formation of trisulfide bridges by $\mathrm{H}_{2} \mathrm{~S}$ is the origin of the effect. ${ }^{[5]}$

While not questioning this correlation, we start from a different perspective in establishing the source of the underlying $\mathrm{H}_{2} \mathrm{~S}$ connection. This derives from our recent studies, ${ }^{[6,7]}$ in which we showed that the addition of other species (in these cases an acid molecule, $\mathrm{HCl}$ ) to the environment (milieu) of a hydrated peptide can invert the relative energies (the propensity) of the two local peptide conformations that are relevant to the formation of plaques: the (3-fold left-handed helical) polyproline II (P), which we demonstrated ${ }^{[8,9]}$ and has been substantiated, ${ }^{[10]}$ is the basic local conformation in the aqueous unordered state and the (extended) $\beta$. Hydrogen bonding of the latter to other such $A \beta$ peptides can account for the plaque formation in AD. It is therefore appropriate to determine if this propensity in peptides is sensitive to the concentration of $\mathrm{H}_{2} \mathrm{~S}$ added to the aqueous milieu. In this study we do so through ab initio calculations of relevant hydrated alanine dipeptides (ADP). 


\section{2 | CALCULATIONS}

The possible sensitivity of the P- $\beta$ propensity of the hydrated ADP molecule, $\mathrm{CH}_{3}-\mathrm{CONH}-\mathrm{CH}\left(\mathrm{CH}_{3}\right)-\mathrm{CONH}-\mathrm{CH}_{3}$, to the concentration of environmental $\mathrm{H}_{2} \mathrm{~S}$ was determined by the following protocol: (a) An ADP molecule was surrounded by 18 water molecules, 6 placed in hydrogenbonded positions at the $\mathrm{CO}$ and $\mathrm{NH}$ groups and the other 12 distributed in various likely bonding positions to these waters. (b) Starting with canonical values of $\varphi, \psi\left(P,-75^{\circ}, 145^{\circ}\right.$ and $\left.\beta,-134^{\circ}, 145^{\circ}\right)$ these preliminary structures were ab initio minimized, resulting in $\varphi, \psi$ of $P,-84^{\circ}$, $147^{\circ}$ and $\beta,-154^{\circ}, 146^{\circ}$ and of course the finding that the energy of $\mathbf{P}$ is lower than that of $\beta$ (by $2.44 \mathrm{kcal} / \mathrm{mol}$ ). (c) The low-concentration case was modelled by the interaction of a single $\mathrm{H}_{2} \mathrm{~S}$ molecule with this system, and the sampling of the $\mathrm{P}$ and $\beta$ energy regions was done by placing this molecule in a variety of initial positions (a total of some 20 on the surfaces of, within the water interior of the $\operatorname{ADP}\left(\mathrm{H}_{2} \mathrm{O}\right)_{18}$, and hydrogen bonding to the peptide) and, starting with the above $\varphi, \psi$, minimizing each structure. (d) The high-concentration case was assumed to be represented by the interaction of two $\mathrm{H}_{2} \mathrm{~S}$ molecules with the hydrated $\mathrm{ADP}$, and with a similar set of starting positions the new energy minimizations were obtained. These sets of results provided the lowest and associated higher-energy minima in each of the $P$ and $\beta$ energy basins (which, obviously, are not smooth). For descriptive purposes we designate the global energy minimum for each $\mathrm{H}_{2} \mathrm{~S}$ concentration as zero and present those of the higher energies that were less than about $7 \mathrm{kcal} / \mathrm{mol}$.

Calculations were done with Gaussian 09, ${ }^{[11]}$ with the dispersion-corrected $w B 97 X-D$ functional ${ }^{[12]}$ and the $6-31++G^{* *}$ basis set. A polarized continuum model reaction field was included at the start to ensure that polarization effects from a surrounding medium, particularly relevant for the $\mathrm{H}_{2} \mathrm{~S}$ molecules, were incorporated during the energy minimization. Atomic charges were determined as natural population analysis charges. The $P$ - $\beta$ propensity is determined by the relative energies of the lowest minima in the $\mathrm{P}$ and $\beta$ regions of the energy landscape.

\section{3 | RESULTS AND DISCUSSION}

In Table 1 we present calculated energies in the two conformational basins and the charges on the peptides in the respective lowest minimum in each. It is clear that the $\beta$ conformation prevails in the single $\mathrm{H}_{2} \mathrm{~S}$ form whereas the $\mathrm{P}$ conformation prevails in the double $\mathrm{H}_{2} \mathrm{~S}$ state. In the light of our previous studies, ${ }^{[6,7]}$ it is not surprising that in the first case this milieu (as well as the complex environment in the brain) would enhance the prevalence of the local $\beta$ conformation, thus providing our previously demonstrated energetic basis for forming the hydrogen-bonded structures that result in amyloid plaques. ${ }^{[7]}$ What is perhaps unexpected is that the $\mathrm{P}$ propensity in the second case (and in the comparably higher $\mathrm{H}_{2} \mathrm{~S}$ concentration in the normal brain environment) can result just from the addition of another $\mathrm{H}_{2} \mathrm{~S}$ molecule interacting with this ADP system, returning it to the individual unordered, and therefore soluble, chain structures that prevail for these peptides in the normal brain. It is also of interest that the
TAB LE 1 Relative energies of minimized $P$ and $\beta$ conformations of $\operatorname{ADP}\left(\mathrm{H}_{2} \mathrm{O}\right)_{18}\left(\mathrm{H}_{2} \mathrm{~S}\right)$ and $\mathrm{ADP}\left(\mathrm{H}_{2} \mathrm{O}\right)_{18}\left(\mathrm{H}_{2} \mathrm{~S}\right)_{2}$

\begin{tabular}{|c|c|c|c|c|c|}
\hline \multicolumn{3}{|l|}{$P$} & \multicolumn{3}{|l|}{$\boldsymbol{\beta}$} \\
\hline$\varphi, \psi$ & $\Delta E^{\mathrm{a}}$ & $q(\text { pep })^{b}$ & $\varphi, \psi$ & $\Delta E^{\mathrm{a}}$ & $q(\text { pep })^{b}$ \\
\hline \multicolumn{6}{|c|}{$\operatorname{ADP}\left(\mathrm{H}_{2} \mathrm{O}\right)_{18}\left(\mathrm{H}_{2} \mathrm{~S}\right)$} \\
\hline$-103^{\circ}, 143^{\circ}$ & 2.51 & 0.1 & $-162^{\circ}, 144^{\circ}$ & 0 & 12 \\
\hline$-77^{\circ}, 156^{\circ}$ & 3.13 & & $-164^{\circ}, 133^{\circ}$ & 1.07 & \\
\hline$-100^{\circ}, 110^{\circ}$ & 6.05 & & $-151^{\circ}, 145^{\circ}$ & 5.75 & \\
\hline \multicolumn{6}{|c|}{$\operatorname{ADP}\left(\mathrm{H}_{2} \mathrm{O}\right)_{18}\left(\mathrm{H}_{2} \mathrm{~S}\right)_{2}$} \\
\hline$-86^{\circ}, 128^{\circ}$ & 0 & -27 & $-143^{\circ}, 140^{\circ}$ & 4.22 & 11 \\
\hline$-89^{\circ}, 138^{\circ}$ & 6.92 & & $-128^{\circ}, 141^{\circ}$ & 7.06 & \\
\hline
\end{tabular}

${ }^{a}$ Energy in $\mathrm{kcal} / \mathrm{mol}$ above minimum.

${ }^{\mathrm{b}}$ Charge in millielectrons (me).

change in peptide charge in the $\mathrm{H}_{2} \mathrm{~S}$ case from a $\mathrm{P}$ minimum ( $-27 \mathrm{me}$ ) to a $\beta$ minimum (12 me) is in the same positive direction but is very much larger than the similar positive change, from 28 to $36 \mathrm{me}$, in the case of a hydrated alanine tripeptide with an added $\mathrm{HCl}$ in the milieu. ${ }^{[7]}$ This reflects the close relationship between charge transfer and the hydrogen-bond energetics of the water structures interacting with the peptide. ${ }^{[13]}$ Detailed examination of the molecular structures of the two conformations in each of the $\mathrm{H}_{2} \mathrm{~S}$ states indicates that the propensity difference resides in the different peptide-water organizations that result from the nearby $\mathrm{H}_{2} \mathrm{~S}$-water interactions (including those originating from initial $\mathrm{H}_{2} \mathrm{~S}$-peptide hydrogen-bonded placements) that are analogous to those associated with the solubilization of $\mathrm{H}_{2} \mathrm{~S}$ in water. ${ }^{[14]}$

While our present analysis encompasses the basic molecular energetic interactions characteristic of the conformations of hydrated peptide chains, its application to the study of specific properties of real peptide systems must depend on the ability to understand the behavior of longer chains and of other side chains. Such information cannot come from the current computationally limited ab initio approach used in this study and will have to involve extensions to free energy results and to the use of molecular dynamics simulations. However, the latter still cannot be depended on to include in their energy functions all of the physics that is inherent in the ab initio approach. As we pointed out, ${ }^{[7]}$ even using simplified approximations, such as the rigid waters that are often assumed, can lead to gross errors. Repeating our present computations with rigid water constraints, while they maintain the structure and $\mathrm{P}$ propensity for the $2 \mathrm{H}_{2} \mathrm{~S}$ case they invert the propensity in the single $\mathrm{H}_{2} \mathrm{~S}$ case, favoring $\mathrm{P}$ over $\beta$ by $4.64 \mathrm{kcal} / \mathrm{mol}$ and with a peptide charge of $-17 \mathrm{me}$ (compared to 12 me for the flexible water). Clearly, all of the relevant properties of hydrogen-bond interactions that are necessary for determining energies and charge transfers must be incorporated in such simulations in order to accurately predict the subtle structural preferences in such molecular systems ${ }^{[15]}$ (i.e., "to get the physics right" $\left.^{\prime[16]}\right)$. Despite this absence it should be expected that the basic physical properties revealed here for a simple peptide system are also operational in more general peptide structures. 


\section{4 | CONCLUSIONS}

Our demonstration that a low $\mathrm{H}_{2} \mathrm{~S}$ concentration in the hydrated environment of a peptide can favor a local $\beta$ over a $\mathrm{P}$ chain conformation whereas a high concentration favors $P$ over $\beta$ has more general implications. The number of amyloid diseases, neurodegenerative and not, is very large (a recent review describes about $70^{[17]}$ ) and although the initial bonding leads to insoluble fibrils ${ }^{[17]}$ that can then aggregate in many polymorphic forms ${ }^{[18]}$ (such as the amyloid plaques of $A D$ ) it is now evident that the basic source of this outcome is the physical drive from the environment for the peptide to adopt a specific (i.e., $\beta$ ) local conformation. Since the peptide is thus undergoing a natural response to its environment, we prefer to characterize these ailments as "protein milieu-folding diseases." ${ }^{\text {[7] }}$ (Such results can also occur in nominally non-disease situations, as evidenced in the finding of amyloid in human cataracts. ${ }^{[19]}$ ).

Adopting the milieu-folding paradigm also points to potentially useful research directions in preventing amyloid illnesses. This is in the spirit that rather than efforts to destroy the plaques after they have been formed it makes more sense to prevent them from forming in the first place. In the present case an obvious path would be to investigate the causes that determine an onset of the $\mathrm{H}_{2} \mathrm{~S}$ depletion in the normal brain that we now know is associated with the development of $A D$ (genetic? lifestyle? environmental? etc.).

\section{ACKNOWLEDGMENTS}

As before, a major portion of our calculations was made possible by the donation of time on the computational facilities of Charles L. Brooks, III. For this we are deeply grateful.

\section{CONFLICT OF INTEREST}

The authors declare no competing interests.

\section{REFERENCES}

[1] P. Rose, P. K. Moore, Y. Z. Zhu, Cell. Mol. Life Sci. 2017, 74, 1391.

[2] K. Eto, T. Asada, K. Arima, T. Makifuchi, H. Kimura, Biochem. Biophys. Res. Commun. 2002, 293, 1485.

[3] E. Vandini, A. Ottani, D. Zaffe, A. Calevro, F. Canalni, G. M. Cavallini, R. Rossi, S. Guarini, D. Giuliani, Pharmacology 2019, 103, 50.

[4] A. Habib, D. Sawmiller, J. Tan, J. Neurosci. Res. 2017, 95, 973.

[5] M. Rosario-Alomar, T. Quinones-Ruiz, D. Kurouski, V. Sereda, E. B. Ferreira, L. D. Jesus-Kim, S. Hernandez-Rivera, D. V. Zagorevski, J. Lopez-Garriga, I. K. Lednev, J. Phys. Chem. B 2015, 119, 1265.

[6] N. G. Mirkin, S. Krimm, Biopolymers 2016, 105, 305.

[7] N. G. Mirkin, S. Krimm, J. Phys. Chem. B 2018, 122, 4428.

[8] M. L. Tiffany, S. Krimm, Biopolymers 1968, 6, 1379.

[9] S. Krimm, M. L. Tiffany, Isr. J. Chem. 1974, 12, 189.

[10] M. Mezei, P. J. Fleming, R. Srinivasan, G. D. Rose, Proteins Struct. Funct. Bioinform. 2004, 55, 502.

[11] M. J. Frisch, G. W. Trucks, H. B. Schlegel, G. E. Scuseria, M. A. Robb, J. R. Cheeseman, G. Scalmani, V. Baroni, G. A. Petersson, H. Nakatsuji, et al., Gaussian 09, Revision A.2, Gaussian, Wallingford, CT 2009.

[12] J. Chai, M. Head-Gordon, Phys. Chem. Chem. Phys. 2008, 10, 6615.

[13] N. G. Mirkin, S. Krimm, J. Chem. Phys. 2014, 140, 046101.

[14] S. Riahi, C. Rowley, J. Phys. Chem. B. 2014, 118, 1373.

[15] N. G. Mirkin, S. Krimm, Biopolymers. 2012, 97, 789.

[16] A. Nicholls, J. Comput. Aided Mol. Des. 2012, 26, 103.

[17] F. Chiti, C. M. Dobson, Ann. Rev. Biochem. 2017, 86, 27.

[18] D. S. Eisenberg, M. R. Sawaya, Ann. Rev. Biochem. 2017, 86, 69.

[19] A. M. Alperstein, J. S. Ostrander, T. O. Zhang, M. T. Zanni, PNAS $2019,116,4602$.

How to cite this article: Mirkin NG, Krimm S. Hydrogen sulfide concentration in the milieu of the hydrated alanine dipeptide determines its polyproline II-beta propensity: Main chain contribution to the energetic origin of the formation of amyloid. Biopolymers. 2020;111:e23356. https://doi.org/10. 1002/bip.23356 